\title{
The asthma-COPD overlap syndrome: a new entity?
}

\author{
Miriam Barrecheguren, Cristina Esquinas and Marc Miravitlles ${ }^{*}$
}

\begin{abstract}
Summary
Asthma and COPD are the most frequent chronic respiratory diseases. Although they have different characteristics, some individuals share features of both diseases, which has been called the asthma-COPD overlap syndrome (ACOS). Although there is not a universally accepted definition for ACOS, it was initially defined as symptoms of increased variability of airflow in association with an incompletely reversible airflow obstruction. The most recent COPD guidelines include this phenotype and its diagnostic features.

Patients with ACOS are usually characterized by increased reversibility of airflow obstruction, eosinophilic bronchial and systemic inflammation, and increased response to inhaled corticosteroids, compared with COPD patients. The relevance of the ACOS is the need to identify patients with COPD who may have underlying eosinophilic inflammation that responds better to inhaled corticosteroids. Until new diagnostic tools are developed, a previous diagnosis of asthma in a patient with COPD can be a reliable criterion to suspect ACOS in a patient with COPD but a comprehensive approach may be required in most cases for a definitive diagnosis of ACOS.
\end{abstract}

Keywords: COPD, Asthma, ACOS, Phenotypes, Treatment

\section{Introduction}

Chronic obstructive pulmonary disease (COPD) is an underdiagnosed disease with a high morbidity and mortality and is a very significant public health problem. In Europe the estimated prevalence varies from $2.1 \%$ and $26.1 \%$ between countries [1]. Given its high prevalence, COPD entails a high burden in all the levels of care.

In recent years, there has been a growing interest in defining and characterising COPD patients into different phenotypes that share clinical features, similar response to the available treatments and that may have prognostic implications [2, 3]. Among these, the asthma-COPD overlap syndrome (ACOS) is a clear example that fulfils all the criteria and is currently kindling great interest.

COPD and asthma have clear differences, but some patients may present with a mixture of both diseases. ACOS may be a manifestation of characteristics of the asthma and COPD that the patient is suffering from. Clinically, the ACOS usually corresponds to asthmatic smokers who develop non-fully reversible airway obstruction, however,

\footnotetext{
*Correspondence: mmiravitlles@vhebron.net

Pneumology Department, Hospital Universitari Vall d'Hebron. Ciber de Enfermedades Respiratorias (CIBERES), P. Vall d'Hebron 119-129, 08035 Barcelona, Spain
}

\section{Definition and clinical features}

From a COPD perspective, the identification of ACOS is relevant to describe a subgroup of smokers with COPD that share some pathogenic and inflammatory characterwith asthma. Patients with ACOS are also more ikely to be frequent exacerbators (defined as the presence of 2 or more exacerbations per year), to have reduced physical activity, worse quality of life and more

when the previous history of asthma is unknown, the diagnesis of ACOS may be difficult due to the lack of specific will require a comprehensive approach including clinical manifestations, spirometry with bronchodilator test, identification of eosinophilic inflammation, lung volumes and and such diagnosis should be made by a specialist [4].

The interest in recognizing these individuals lies in their better response to inhaled corticosteroids (ICS) compared to those with COPD. This specific and differential treatment justifies the efforts to differentiate the subgroup of patients with ACOS from the large population of COPD patients. 
respiratory symptoms, particularly dyspnoea and wheezing, than patients with COPD alone [5, 6].

ACOS has been defined as symptoms of increased variability of airflow in association with incompletely reversible airflow obstruction [7]. More recently, Louie et al. [8] defined ACOS as asthma with partially reversible airflow obstruction, with or without emphysema or reduced carbon monoxide diffusing capacity (DLCO) to $<80 \%$ predicted, and COPD with emphysema accompanied by reversible or partially reversible airflow obstruction, with or without environmental allergies or reduced DLCO. Izquierdo-Alonso et al. [9] identified ACOS as patients with COPD (more than 10 pack-years of smoking and post-bronchodilator $\mathrm{FEV} 1 / \mathrm{FVC}<0.7$ ) and a personal history of asthma before the age of 40 , with the addition of normal carbon monoxide $(\mathrm{CO})$ diffusing capacity and the absence of pulmonary emphysema demonstrated by imaging techniques.

It is important to recognise that the presence of chronic non-fully reversible airflow obstruction in a subject with asthma is not necessarily ACOS. It is well known that severe asthma patients may develop non-reversible airflow limitation without any characteristics of COPD [10].

The definition of ACOS is also included in some of the latest guidelines. The Spanish guidelines of COPD identify ACOS patients based on some diagnostic criteria: A) Major criteria: very positive bronchodilator response $(>400 \mathrm{ml}$ and $>15 \%$ in FEV1), sputum eosinophilia or previous diagnosis of asthma. B) Minor criteria: increased total serum IgE, previous history of atopy or positive bronchodilator test $(>200 \mathrm{~mL}$ and $>12 \%$ in FEV1) on at least two occasions [11, 12]. To be diagnosed with ACOS, a patient must fulfil two major or one major and two minor criteria. The recent Czech Republic and Finnish guidelines also include ACOS with its own diagnostic criteria. In the Czech Republic diagnostic guidelines major criteria include a strong bronchodilator test positivity (FEV1 $>15 \%$ and $>400 \mathrm{ml}$ ), positive bronchial challenge test, FeNO $>45-50 \mathrm{ppb}$ and/or sputum eosinophilia $\geq 3 \%$ and a previous histoy of asthma, and as minor criteria: mild bronchodilator test positivity (FEV1 $>12 \%$ and $>200 \mathrm{ml}$ ), increased total IgE and history of atopy [13]. The main Finnish diagnostic criteria are also a significant bronchodilatory effect (FEV1 $>15 \%$ and $>400 \mathrm{ml}$ ), sputum eosinophilia or elevated ENO ( $>50 \mathrm{ppb})$ and previous asthma symptoms (starting before the age of 40). As additional criteria they include an elevated total IgE, atopy, repeated significant bronchodilatory response (FEV1 $>12 \%$ and $>200 \mathrm{ml}$ ) and a PEF-follow up typical of asthma [14]. For both guidelines, a patient must fulfil two major (or main) criteria or one major and two minor (or additional) criteria.

A recent GOLD-GINA document about ACOS describes this syndrome as persistent airflow limitation with several features usually associated with asthma and several features usually associated with COPD [15].

\section{Diagnosis: current and future strategies}

In asthma the term endotype has been introduced to identify subtypes of patients defined by a distinct functional of pathophysiological mechanism [16]. It is possible that different mechanisms in patients suffering from asthma or COPD could lead to the clinical expression that we now define as ACOS. Most studies define ACOS as a phenotype of COPD. There is no unified definition of ACOS but some main features can help us to identify this phenotype. In patients with COPD, increased reversibility is one of the key differential aspects of individuals with ACOS, but it can be misleading if taken alone. Significant reversibility in COPD is common and observed frequently in clinical practice and in series of patients included in clinical trials [17]. Somewhat more than $50 \%$ of the patients with moderate-tovery-severe COPD in the UPLIFT clinical trial met the most commonly used criteria for acute bronchodilator responsiveness [18]. Related to this bronchodilator response, bronchial hyperresponsiveness (BHR) is observed in almost all patients with asthma, especially in those with active symptoms and in up to two-thirds of COPD patients [19]. Furthermore, BHR is observed in aproximately $10 \%$ to $20 \%$ of the general population and has shown to be a risk factor of developing asthma and COPD [8]. In patients with established asthma or COPD, more severe BHR is associated with more severe symptoms and a more rapid decline in FEV1 [20]. Nevertheless, in a population of COPD patients without significant comorbidities, individuals with high levels of reversibility presented better long-term outcomes [21]. These controversial results underscore the need of a specialised approach to the diagnosis and assessment of the patients with ACOS.

Possibly the most important diagnostic feature of ACOS in COPD is the presence of sputum eosinophilia. Inflammation in asthma patients is considered to be mainly eosinophilic and mediated by $\mathrm{CD} 4+\mathrm{T}$ lymphocytes while in COPD it is neutrophillic and driven by CD8+. Papi et al. [22] observed that peripheral eosinophilic counts and sputum eosinophil counts were significantly higher in stable COPD patients with partial reversibility of airflow limitation compared to COPD patients without reversibility. Since sputum eosinophilia is not routinely performed in clinical practice, indirect markers of this type of inflammation have been investigated. Chou et al. [23] demonstrated higher levels of exhaled nitric oxide (eNO) in patients with COPD and eosinophilic airway inflammation ( $>3 \%$ eosinophils in induced sputum), with a cut off of $23.5 \mathrm{ppb}$ of eNO having a sensitivity of $62.1 \%$ and a specificity of $70.5 \%$ for the identification of eosinophilic 
inflammation. Interestingly, patients with COPD and peripheral eosinophilic inflammation treated with ICS present fewer exacerbations compared to those with lower blood count levels [24].

Other plasma and sputum biomarkers of ACOS are currently being studied. Iwamoto et al. [25] investigated four potential biomarkers in COPD (surfactant protein A (SP-A), soluble receptor for advanced glycation end products (sRAGE), myeloperoxidades (MPO) and neutrophil gelatinase associated lipocalin (NGAL)). Compared with asthma patients, sputum MPO and plasma SP-A were significantly elevated in ACOS, while only sputum NGAL was significantly increased compared to COPD. Fu et al. [26] examined the levels of the systemic inflammation markers PCR and IL-6 in asthma, COPD and ACOS patients and identified potential clinical characteristics that were associated with these biomarkers. They found a high prevalence of systemic inflammation in older people with ACOS and an elevated IL-6 compared with asthma patients. Age, Charlson comorbidity index and IL-6 were independently associated with ACOS while IL-6 was independently associated with airflow obstruction and cardiovascular disease suggesting that it may be involved in these two processes and may therefore be an independent treatment target [26].

There is a growing interest in the identification of genetic determinants for ACOS. Genetic analysis of the COPD gene cohort identified several variants associated with ACOS, which may demonstrate distinct genetic risk factors [27]. Christenson et al. [28] investigated whether asthma-associated gene signatures were increased in a subgroup of COPD patients and associated with asthmarelated features, consisting in eosinophilia and type 2 (TH2) inflammation. In their study, the investigators developed a 100 gene signature of the Th2-related gene expression, the T2S score that correlated well with Th2associated clinical characteristics in asthmatic patients and found that approximately $20 \%$ of their COPD patients had increased expression of T2S. They next investigated the association of T2S with clinical parameters in the GLUCOLD cohort of patients with COPD. T2S was significantly associated with increased tissue eosinophil numbers, increased serum eosinophil percentage and increased bronchodilator responsiveness (Fig. 1). Interestingly, a higher T2S was associated with greater reduction in hyperinflation after ICS (with or without LABA) treatment versus placebo at 30 months [28]. Nevertheless, albeit promising, these techniques are not available in every centre and cannot yet be used as a diagnostic tool in clinical practice.

\section{Epidemiology of ACOS}

Data derived from large population studies have revealed that a high proportion of adult patients with respiratory symptoms are commonly diagnosed with more than one obstructive lung disease, especially elderly individuals [29].

More interesting is the prevalence of ACOS observed among populations of patients diagnosed with COPD. This prevalence can be estimated from research databases or clinical studies. The prevalence of ACOS derived from clinical studies is usually lower compared with the analysis of databases, due to the use of more restrictive diagnostic criteria. Using the criteria established by the Spanish National Consensus Conference (Table 1), in a cross sectional study with 279 COPD patients Miravitlles et al. [30] observed a prevalence of ACOS of $5 \%$. A larger survey in 3125 COPD patients using the same

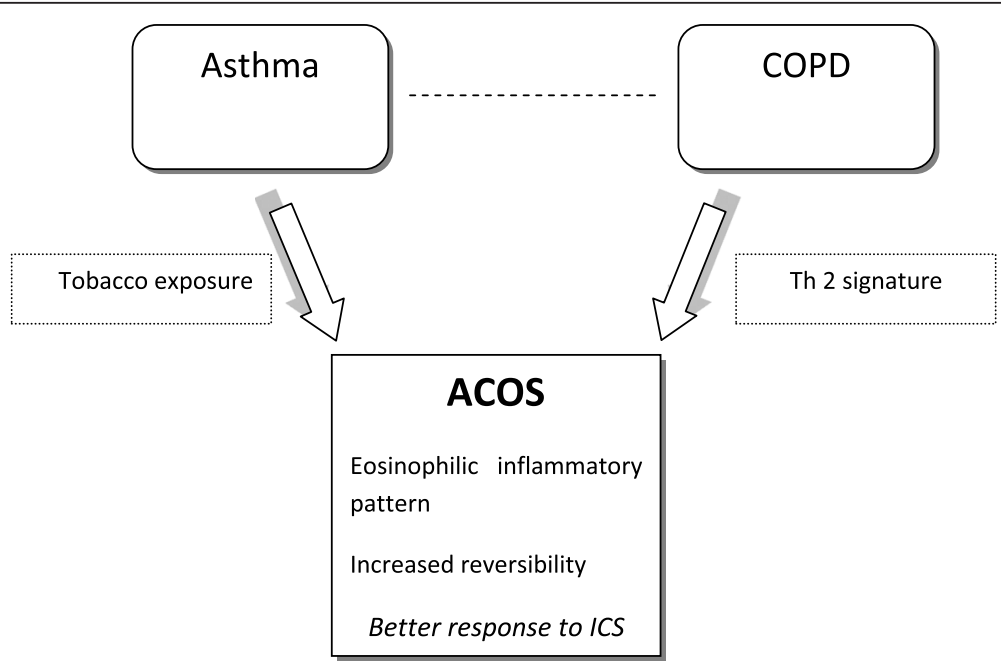

Fig 1 Clinical expression of the asthma-COPD overlap syndrome (ACOS). The ACOS usually corresponds to a smoker asthmatic patient that develops non fully reversible airway obstruction and/or a COPD individual (with or without a known history of asthma) with a Th2 signature (increased blood and lung eosinophilia, increased airway hyper-responsiveness, and better response to ICS). Reproduced with permission from ref. [43] 
Table 1 Asthma-COPD overlap syndrome, definitions and diagnostic criteria

\begin{tabular}{ll}
\hline Gibson P, Simpson J [7], 2009 & $\begin{array}{l}\text { Asthma and COPD (symptoms of increased variability of airflow and incompletely rever } \\
\text { airflow obstruction) }\end{array}$ \\
COPD gene [5],2011 & Patients with COPD and a diagnosis of asthma before the age of 40 \\
Spanish consensus [1 1], 2012 (patients must fulfill & Major criteria \\
2 major criteria or 1 major and 2 minor) & Very positive bronchodilator response ( $>400 \mathrm{ml}$ and $>15 \%$ in FEV1) \\
& Sputum eosinophilia \\
& Previous diagnosis of asthma \\
& Minor criteria \\
& Increased total serum lgE \\
& Previous history of atopy \\
& Positive bronchodilator test $(>200 \mathrm{~mL}$ and $>12 \%$ in FEV1) on at least two occasions
\end{tabular}

Czech Republic guidelines [13], 2013 (patients must Major criteria fulfill 2 major criteria or 1 major and 2 minor)

Strong bronchodilator test positivity (FEV1 > $15 \%$ and $>400 \mathrm{ml}$ )

Positive bronchial challenge test

FeNO > 45-50 ppb and/or sputum eosinophilia $\geq 3 \%$

Histoy of asthma

Minor criteria

Mild bronchodilator test positivity (FEV1 > $12 \%$ and $>200 \mathrm{ml}$ )

Increased total lgE

History of atopy

Louie S et al. [8], 2013

Menezes M et al. [30], 2013

Izquierdo-Alonso et al. [9] (2013)

GOLD-GINA document [15] (2014)

Finish guidelines [14] (2014) (patients must fulfill 2 main criteria or 1 main and 2 additional)
-Asthma with partially reversible airflow obstruction with/without emphysema or reduction of DLCO $<80 \%$ predicted.

-COPD with emphysema accompanied by reversible or partially reversible airflow obstruction, with or without environmental allergies or reduced DLCO

FEV1/FVC $<0.7$ and medical diagnosis of asthma or wheezing + positive bronchodilator test ( $>200 \mathrm{~mL}$ and $>12 \%$ in FEV1)

COPD (more than 10 pack-years and post bronchodilator FEV1/FVC $<0.7$ )

History of asthma before the age of 40

Normal carbon monoxide (CO) diffusion capacity and absence of pulmonary emphysema demonstrated by imaging techniques

Persistent airflow limitation with several features usually associated with asthma and several features usually associated with COPD

Main criteria

Significant bronchodilatory effect (FEV1 $>15 \%$ and $>400 \mathrm{ml}$ )

Sputum eosinophilia or elevated ENO (>50 ppb)

Previous asthma symptoms (starting before the age of 40)

Additional criteria

Elevated total IgE

Atopy

Repeated significant bronchodilatory response (FEV1 > $12 \%$ and > $200 \mathrm{ml}$ )

PEF-follow up typical of asthma criteria observed a prevalence of ACOS of $3.9 \%$. However, this prevalence increased to $15.9 \%$ when using the criterion of a previous diagnosis of asthma [31]. In a retrospective observational study of 499 patients with COPD Golpe et al. [32] observed a similar prevalence (5\%) in smoking-related COPD patients but with a higher frequency of ACOS in COPD patients caused by inhalation of biomass smoke $(21.2 \%)$. Following modified criteria from the Spanish consensus that included a normal diffusion capacity for carbon monoxide (DLCO), Izquierdo-Alonso et al. [9] detected a prevalence of ACOS of $12 \%$ in an observational, multicentre study 
performed in 331 COPD patients recruited in pulmonology outpatient services. Similar frequencies have been described in studies performed in other countries [5, 8]. In the COPD Gene study, Hardin and colleges found that $13 \%$ of subjects with COPD also reported physiciandiagnosed asthma [5]. In epidemiological studies such as the PLATINO study performed in Latin America, a prevalence of $11.6 \%$ was described using a postbronchodilator $\mathrm{FEV} 1 / \mathrm{FVC}<0.7$ and asthma diagnosis as ACOS criteria [33]. In the Spanish EPISCAN epidemiological study, including patients with COPD and previous diagnosis of asthma before the age of 40 , a prevalence of $17.4 \%$ of ACOS was observed among the COPD population [34].

\section{Treatment}

There is little information about the response of ACOS patients to most of the current pharmacological therapies as they have been systematically excluded from both COPD and asthma pharmacological trials. The only clinical trial performed to date in patients with ACOS studied the effects of tiotropium in 472 individuals with concomitant COPD and asthma. Improvements in lung function and a reduction in rescue medication were observed with tiotropium [35]. However, the main interest in differentiating ACOS from COPD lies in the different response to ICS. Some studies demonstrate that patients with COPD and eosinophilic inflammation treated with ICS present a significant improvement in bronchial inflammation together with clinical and spirometric improvement [36, 37]. Two small, randomised trials have demonstrated that prescribing corticosteroids (oral or inhaled) according to the intensity of bronchial eosinophilic inflammation in patients with COPD was significantly superior in preventing exacerbations and improving health-related quality of life compared with the prescription of ICS according to current guidelines [38, 39].

Already in 2007 the Canadian guidelines specified that: "if the asthma component (in COPD) is prominent, earlier introduction of ICS may be justified" [40]. Later, in 2010, the Japanese guidelines of COPD dedicated a chapter to "Treatment of COPD complicated by asthma" [41] and indicate that ICS combined with long-acting beta-2 agonists (LABA) would be the first choice treatment irrespective of the level of airflow obstruction. More recently, the Spanish guidelines of COPD, the Czech Republic guidelines and the Finnish guidelines address the indication of ICS in the patients with ACOS in all stages of severity $[13,14]$.

New treatments targeting a reduction in eosinophilic concentrations are being developed. Among them, the anti-IL5 benralizumab has not proven to reduce exacerbations in COPD patients with peripheral eosinophilia, but patients with the highest eosinophilic count showed improvements in FEV1 and a reduction in the exacerbations rate, which support further investigation [42].

\section{Conclusion}

Patients with ACOS show 3 characteristic features that help us to identify them: enhanced bronchial and systemic eosinophilic inflammation, increased reversibility of airflow and increased response to ICS compared with patients with COPD alone. Whether one believes in the existence of ACOS or just in the coexistence of these two different diseases in the same individual, it is clear that patients with ACOS are different from those with asthma and COPD. Although these patients share features with both asthma and COPD, they have some different clinical characteristics and prognosis and what it more important, a better response to ICS.

\section{Abbreviations}

ACOS: Asthma-COPD overlap disease; COPD: Chronic obstructive pulmonary disease; ICS: inhaled corticosteroids; BHR: bronchial hyperresponsiveness; LABA: long acting $\beta 2$ agonist; DLCO: carbon monoxide diffusing capacity; CO: carbon monoxide; SP-A: surfactant protein A; SRAGE: soluble receptor for advanced glycation end products; MPO: mieloperoxidase; NGAL: neutrophil gelatinase associated lipocalin.

\section{Competing interests}

Marc Miravitlles has received speaker fees from Almirall, Boehringer Ingelheim, Pfizer, AstraZeneca, Chiesi, Esteve, GlaxoSmithKline, Menarini, Grifols, Nycomed, and Novartis, and consulting fees from Almirall, Boehringer Ingelheim, Pfizer, GlaxoSmithKline, Gebro Pharma, CLS Behring, Medilmmune, Novartis, Grifols and Nycomed. Miriam Barrecheguren and Cristina Esquinas have no conflict of interest to disclose.

\section{Authors' contributions}

All authors wrote, read and approved the final manuscript.

Received: 25 May 2015 Accepted: 24 August 2015

Published online: 22 October 2015

\section{References}

1. Atsou K, Chouaid C, Hejblum G. Variability of the chronic obstructive pulmonary disease key epidemiological data in Europe: systematic review. BMC Med. 2011;9:7.

2. Han MK, Agusti A, Calverley PM, Celli BR, Criner G, Curtis JL, et al. Chronic obstructive pulmonary disease phenotypes: the future of COPD. Am J Respir Crit Care Med. 2010;182:598-604.

3. Miravitlles M, Calle M, Soler-Cataluña JJ. Clinical phenotypes of COPD Identification, definition and implications for guidelines. Arch Bronconeumol. 2012;48:86-98.

4. Miravitlles M, Alcázar B, Alvarez FJ, Bazús T, Calle M, Casanova C, et al. What pulmonologists think about the asthma-COPD overlap syndrome (ACOS). Int J Chron Obst Pulm Dis. 2015;10:1321-30.

5. Hardin M, Silverman EK, Barr RG, Hansel NH, Schroeder JD, Make BJ, et al. The clinical features of overlap between COPD and asthma. Respir Res. 2011;12:127

6. Barrecheguren M, Esquinas C, Miravitlles M. The asthma-chronic obstructive pulmonary disease overlap syndrome (ACOS): opportunities and challenges. Curr Opin Pulm Med. 2015;21:74-9.

7. Gibson PG, Simpson JL. The overlap syndrome of asthma and COPD: what are its features and how important is it? Thorax. 2009;64:728-35.

8. Louie S, Zeki AA, Schivo M, Chan AL, Yoneda KY, Avdalovic M, et al. The asthma-chronic obstructive pulmonary disease overlap syndrome: pharmacotherapeutic considerations. Expert Rev Clin Pharmacol. 2013;6:197-219

9. Izquierdo-Alonso JL, Rodriguez-Gonzálezmoro JM, de Lucas-Ramos P Unzueta I, Ribera X, Antón E, et al. Prevalence and characteristics of 
three clinical phenotypes of chronic obstructive pulmonary disease (COPD). Respir Med. 2013;107:724-31.

10. Contoli M, Baraldo S, Marku B, Casolari P, Marwick JA, Turato G, et al. Fixed airflow obstruction due to asthma or chronic obstructive pulmonary disease: 5-year follow-up. J Allergy Clin Immunol. 2010;125:830-7.

11. Soler-Cataluña JJ, Cosío B, Izquierdo JL, López-Campos JL, Marín JM, Agüero $R$, et al. Consensus document on the overlap phenotype COPDasthma in COPD. Arch Bronconeumol. 2012:48:331-7.

12. Miravitlles M, Soler-Cataluña JJ, Calle M, Molina J, Almagro P, Quintano JA, et al. Spanish quideline for COPD(GesEPOC) update. Arch Bronconeumol. 2014;50:1-16.

13. Koblizek V, Chlumsky J, Zindr V, Neumannova K, Zatroukal J, Zak J, et al. Chronic Obstructive Pulmonary Disease: Official diagnosis and treatment guidelines Biomed of the Czech Pneumological and Phthisiological society: a novel phenotypic approach to COPD with patient oriented care. Pap Med Fac Univ Palacky Olomouc Czech Repub. 2013;157:189-201.

14. Kankaanranta H, Harju T, Kilpeläinen M, Mazur W, Lehto J, Katajisto M, et al. Diagnosis and pharmacotherapy of Stable Chronic Obstructive Pulmonary Disease: The Finish Guidelines. Basic Clin Pharmacol Toxicol. 2015;116:291-307.

15. GINA-GOLD Diagnosis of disease of chronic airflow limitation: Asthma, COPD and asthma-COPD overlap syndrome (ACOS). Available at: http:// www.goldcopd.org/asthma-copd-overlap.html (accessed August 5th, 2014).

16. Lötvall J, Akdis CA, Bacharier LB, Bjermer L, Casale TB, Custovic A, et al. Asthma endotypes: a new approach to classification of disease entities within the asthma syndrome. J Allergy Clin Immunol. 2011;127:355-60.

17. Welte T, Miravitlles M, Hernandez P, Eriksson G, Peterson S, Polanowski T, et al. Efficacy and tolerability of the addition of budesonide/formoterol to tiotropium in COPD patients. Am J Respir Crit Care Med. 2009;180:741-50.

18. Tashkin DP, Celli B, Decramer M, Liu D, Burkhart D, Cassino C, et al. Bronchodilator responsiveness in patients with COPD. Eur Respir J. 2008;31:742-50.

19. Nakawah MO, Hawkins C, Barbandi F. Asthma, chronic obstructive pulmonary disease (COPD), and the overlap syndrome. J Am Board Fam Med. 2014:26:470-7.

20. Papaiwannou A, Zarogoulidis P, Porpodis K, Spyratos D, Kioumis I, Pitsiou G, et al. Asthma-chronic obstructive pulmonary disease overlap syndrome (ACOS): current literature review. J Thorac Dis. 2014;146-151.

21. Marín JM, Ciudad M, Moya V, Carrizo S, Bello S, Piras B, et al. Airflow reversibility and long-term outcomes in patients with COPD without comorbidities. Respir Med. 2014;108:1180-8.

22. Papi A, Romagnoli M, Baraldo S, Braccioni F, Guzzinati I, Saetta M, et al. Partial reversibility of airflow limitation and increased exhaled NO and sputum eosinophilia in chronic obstructive pulmonary disease. AM J Respir Crit Care Med. 2000;162:1773-7.

23. Chou KT, Su KC, Huang SF, Hsiao YH, Tseng CM, Su VY, et al. Exhaled nitric oxide predicts eosinophilic airway inflammation in COPD. Lung. 2014;192:499-504.

24. Pascoe S, Locantore N, Dransfield M, Barnes NC, Pavord ID. Blood eosinophil counts, exacerbations and response to the addition of inhaled fluticasone furoate to vilanterol in patients with chronic obstructive pulmonary disease: a secondary analysis of data from two parallel randomized controlled trials. Lancet Respir Med 2015 pii: S2213-2600(15)00106-X. doi: 10.1016/S2213-2600(15)00106-X

25. Iwamoto H, Gao J, Koskela J, Kinnula V, Kobayashi H, Laitinen T, et al. Differences in plasma and sputum biomarkers between COPD and COPDasthma overlap. Eur Respir J. 2014;43:421-9.

26. Fu JJ, McDonald V, Gibson P, Simpson JL. Systemic inflammation in older adults with Asthma-COPD overlap syndrome. Allergy Asthma Immunol Res. 2014;6(4):316-24.

27. Hardin M, Cho M, McDonald M-L, Beaty T, Ramsdell J, Bhatt S, et al. The clinical and genetic features of COPD-asthma overlap syndrome. Eur Respir J. 2014;44:341-50.

28. Christenson SA, Steiling K, van den Berge M, Hijazi K, Hiemstra PS, Postma DS, et al. Astha-COPD overlap: clinical relevance of genomic signatures of Type 2 inflammation in COPD. Am J Respir Crit Care Med. 2015;191:758-66.

29. Soriano JB, Davis KJ, Coleman B, Visick G, Mannino D, Pride NB. The proportional Venn diagram of obstructive lung disease. Chest. 2003;124:474-81.

30. Miravitlles M, Huerta A, Fernández-Villar JA, Alcazar B, Villa G, Forné C, et al. Generic utilities in chronic obstructive pulmonary disease patients stratified according to different staging systems. Health Qual Life Outcomes. 2014;12:120
31. Barrecheguren M, Román-Rodríguez M, Miravitlles M. Is a previous diagnosis of asthma a reliable criterion for asthma-COPD overlap syndrome (ACOS) in a patient with COPD? Int J Chron Obstruct Pulmon Dis 2015, In press.

32. Golpe R, Sanjuán López P, Cano Jiménez E, Castro Añón O, Pérez de Llano LA. Distribution of clinical phenotypes in patients with chronic obstructive pulmonary disease caused by biomass and tobacco smoke. Arch Bronconeumol. 2014;50:318-24.

33. Menezes AM, de Oca MM, Pérez-Padilla R, Nadeaus G, Wehrmeister FC, LópezVarela MV, et al. Increased risk of exacerbation and hospitalization in subjects with an overlap phenotype COPD-asthma. Chest. 2014;145:297-304.

34. Miravitlles M, Soriano JB, Ancochea J, Muñoz L, Duran-Tauleria E, Sánchez G, et al. Characterisation of the overlap COPD-asthma phenotype. Focus on physical activity and health status. Respir Med. 2013;107:1053-60.

35. Magnussen H, Bugnas B, van Noord J, Schmidt P, Gerken F, Kesten S. Improvements with tiotropium in COPD patients with concomitant asthma. Respir Med. 2008;102:50-6.

36. Chanez P, Vignola AM, O'Shaugnessy T, Enander I, Li DJeffery PK, et al. Costicosteroid reversibility inCOPD is related to features of asthma. Am J Respir Care Med. 1997;155:1529-34.

37. Brightling CE, Monteiro W, Ward R, Parker D, Morgan MD, Wardlaw AJ, et al. Sputum eosinophilia and short-termresponse to prednisolone in chronic obstructive pulmonary disease: a randomized controlled trial. Lancet. 2000;356:1480-5

38. Siva R, Green RH, Brightling CE, Shelley M, Hargadon B, McKenna S, et al. Eosinophilic airway inflammation and exacerbations of COPD: a randomised controlled trial. Eur Respir J. 2007;29:906-13.

39. McDonald V, Higgins I, Wood L, Gibson PG. Multidimensional assessment and tailored interventions for COPD: respiratory utopia or common sense? Thorax. 2013;68:691-4.

40. O'Donnell DE, Aaron S, Bourbeau J, Hernandez P, Marciniuk DD, Balter M, et al. Canadian Thoracic Society recommendations for management of chronic obstructive pulmonary disease 2007 update. Can Respir J. 2007;Suppl B:5B-32B.

41. Nagai A, Aizawa H, Aoshiba K, Asano K, Hirata K, Ichinose M, et al. Guidelines for the diagnosis and treatment of COPD. 3rd ed. Tokyo (Japan): The Japanese Respiratory Society. Medical Review Co. Ltd; 2009.

42. Brightling CE, Bleecker ER, Panettieri RA, Bafadhel M, She D, Ward CK, et al. Benralizumab for chronic obstructive pulmonary disease and sputum eosinophilia: a randomised, double blind, placebo- controlled, phase 2a study. Lancet Respir Med. 2014;2:891-901.

43. Barrecheguren M, Esquinas C, Miravitlles M. The asthma-COPD overlap syndrome. Eur Respir Monogr 2015 (in press).

\section{Submit your next manuscript to BioMed Central and take full advantage of:}

- Convenient online submission

- Thorough peer review

- No space constraints or color figure charges

- Immediate publication on acceptance

- Inclusion in PubMed, CAS, Scopus and Google Scholar

- Research which is freely available for redistribution

Submit your manuscript at www.biomedcentral.com/submit
C) Biomed Central 